\title{
A Review on IoT based Electric Vehicle Charging and Parking System
}

\author{
K.S. Phadtare ${ }^{1}$, S.S. Wadkar ${ }^{2}$, S.S. Thorat ${ }^{3}$, A.S. Ghorpade ${ }^{4}$ \\ Dept. of Electrical Enginnering, \\ ADCET Ashta, Shivaji University, Kolhapur, India. .,2,3,4 \\ Mr.A.B. Jadav ${ }^{5}$ \\ Assistant Professor, Dept. of Electrical Enginnering, \\ ADCET Ashta, Shivaji University, Kolhapur, India
}

\begin{abstract}
Currently, we are facing issues related to lack of fuel. So, we are moving towards electrical vehicle. But still people are not ready to prefer electrical vehicle over present ones. It is because of price as well as lack of available charging stations. Even if there are few charging stations are available, it is necessary to spend extra time for charging the vehicle. Also, present day car parking has become a major issue in urban cities. So, by taking in views these issues we can provide a smart parking with charging availability to the most commercial buildings. This will reduce the efforts of roaming for slot of parking. Also, there is no need to invest more time for finding charging station and for charging at charging station. This paper outlines the wireless power transfer technology for EV's and charging systems with IOT. In this paper, reviews of IOT based smart parking methods which are implemented is studied and comparison is done between combined parking and charging system with separated parking and charging system.
\end{abstract}

Keywords- EV-Electrical vehicle, wireless charging, automatic parking, IOT-Internet of things, IPT-Inductive power transfer

\section{INTRODUCTION}

Now-a-days Electrical vehicle is a trending topic and it is also an important part of this smart world. Drawback of electric vehicles is cruising range is typically limited. So, it requires frequent recharging. Not only for electric vehicle but Population is increasing exponentially and the problem is due to this is, increasing traffic volume. All we know that we have limited stock of the fuel on our earth so it is need of time that we must switch to another way and electricity is the best option for it and electric vehicle is example of it. For charging the electric vehicles, Now-a-days mostly used charging method is plug in charging, this method consists of a plug which needs to be connected to the vehicle for start charging. In wireless charging there is no need to ON-OFF the plug. Hence there will be less human interaction; it reduces risk of electric shock due to wired connections. Plug-in EVs have limited travel range and need large and heavy batteries. The wireless charging technology has main advantages is, it increases the traveling range, reduces the battery size and waiting time for charging the vehicle will mitigate. Such advantages will increase the economic and environmental benefits as well as the adoption rates of EVs [16].

Electrical vehicles require a charging station similar to current fuel car require a petrol pump and obviously charging takes some time so it is better to charge the car when it is parked, therefore it is efficient to combine both the charging and parking system which is based on the IoT technology which makes the system user friendly. One can upload information on cloud and simultaneously on smart phones. Car safety while parking is one of the issues faced by people. The internet of things (IoT) is best platform for monitoring the status of WPT system which is able to provide the wider connectivity, modified sensing, information processing and greater flexibility [17]. So, With the help of IoT, it is easy to monitor vehicle parking as well as charging of vehicles when they are parked at the same time that means it helps in synchronized parking. Another important factor of using IoT is we can store data on cloud that we can access anytime from anywhere, which makes life easy and simple. [15] Give an idea about, for charging the car we will need some station where the car can be charged, so we can merge the parking concept as an electric station where the car can be parked as well as it will get charged. Thus, there are many advantages of this system. [1] also mentioned that, the current transportation infrastructure and parking facilities are unable to cope with the influx of vehicles on the road, leading to high ecological and economic damage caused due to time spend in searching for parking spots, for instance. Thus, approaches to support electric vehicles and their charging demands are needed which should be able to use parking and charging infrastructures as efficiently as possible.

\section{LITERATURE REVIEW}

[1] Electrical Vehicles are easy to use and therefore accepted by customers. One important need of it is that it requires comfortable charging and parking space. Proposed model designed to give efficient solution to this by combining these two systems. In this paper the design of system which able to handle free parking slots and scheduling of the charging. Current parking system are unable to deal with all types of vehicles. For Electrical Vehicles there is need of charging facility along with parking. The proposed model provides facility to book the charging space via smartphone. Then system manages all activities related to it on the basis of information like arrival time of vehicle, battery status etc. The main components are customer manager, vehicle manager, map manager and lot manager. The software used is Java Platform and Enterprise Edition (Java EE). Another point take 
into account is security concept. For this it requires user ID which is also use for billing process.

[2] Proposed model is designed for modification of original WSN and RFID system with ZigBee technology which is applied in parking garages. The RFID technology is used for checking in and out of vehicles due its fast and secure operation. There are two sections in proposed system one is monitoring and another is control section. Control section contains sensing element, processing element and display devices. The sequence is sensor nodes, LED display and information and management center respectively. The last one information and management center is main part of the system. In the hardware part it contains ARM7/LCP2148 controlled, ZigBee modules for communication, the reflection sensors and LCD panel. The software used is Keil micro vision, flash magic and express PCB.

A centralized electrical vehicle $(\mathrm{EV})$ recharge scheduling system for parking lots is developed by [3]. This system based on the realistic vehicular parking pattern which focus on individual parking slot. It considers two types of EV based on their mobility. One is regular EVs and another is irregular EVs. Electrical Vehicles require sufficient time for charging. This paper suggests a PLRS system which notices arrival and departure time of vehicle, battery state of $\mathrm{EV}$, distance travelled by it. Then system deigns its own schedule of charging for EVs. This system works for day and night time period. This system contributes to increase the number of recharged Electrical Vehicles as well as parking lot revenues. Proposed system has two layered PLRS system for recharging EVs based on parking patterns of these vehicles.

An IoT based cloud integrated smart parking system is presented by [4]. This proposed smart parking system is on site development of IoT module. IoT is one of the most applicable idea of Smart City. This IoT model is used to monitor and provides information about availability of parking space. It also has one mobile application which provides information about availability of parking space to the user. User can book a parking space using this mobile application. For controlling parking system sensors like Infrared, Passive Infrared (PIR) or ultrasonic sensors are used. Processing unit used is Raspberry pi which communicate between cloud and sensor. The mobile application is platform to connect the system and user. This application is developed in Apache Cordova and Angular Js framework using JavaScript as a programming language. The IBM MQTT cloud server is used for store all data. This system gives real time information regarding the parking space availability in parking area.

Another approach to smart parking system is presented by [5]. Proposed system uses ultrasonic sensor, Arduino Uno, ESP8266-01 Wi Fi module and cloud server i.e. ThingSpeak, mobile application. This IoT based parking platform able to connect and analyses real time situation. This system automatically generate data and execute smart parking. Availability of free space is detected by ultrasonic sensor. The sensor is connected to Arduino module which interface with Wi Fi network. Arduino uno is connected to cloud server via internet connection and upload data on it. The android app is run by software system for this user need to install this application on their smart phone. Parking slot can be booked if needed using this application.
[6] presented a review on Intelligent Wireless Charging Station for Electric Vehicles, induction or magnetic coupling techniques are suitable methods in WPT, for EV charging. In this study, an intelligent WPT system is introduced and simulated to charge EV. The charging process is proscribed by misalignment, innovative method is required to improve flexibility of the EV wireless charging. using finger print method, this technique is able to align transmitting coil with receiving coil automatically. Proposed system is able to save required time, minimize mistakes done by human, minimize use of energy and also able to charge car based on real time information about system. It's quite beneficial in energy saving and electricity cost reduction for EV consumer. For EV charging, Wireless power transfer is a new field of development. The efficiency of resonant inductive coupling for EV charging is showed in this paper and discussed techniques to improve wireless charging performance for high-frequency and high-power application. Various coil alignment methods were discussed and fingerprint method was presented as an economical technique for creating WPT intelligent.

In recent time smart cities are under development and IoT plays main role in it. Problems like traffic jam, limited car parking space and road safety can overcome by IoT. [7] proposed a smart parking system which is on site development of IoT module. This system monitors and analyses the availability of parking slot. In this system all data generated by it is stored on cloud therefore it is known as perfect platform for IoT. Due flexibility of cloud, it can add or remove data from IoT system on real time basis. Suggested system consists of microcontroller, IR sensor, mobile application, buzzer, LED and LCD display.

Another approach to Electrical Vehicle (EV) charging scheduling problem is presented by [8]. This paper studies charging problem under a parking garage which involves total use if time. When EV arrives at entrance of garage it takes information such as arrival time, suggested departure time, current and required battery SOCs and garage's charging management system (CMS). This CMS able to take decision about to admit or to decline the customers charging requirement. It manages the required power supply based on the decision. After completion of process it deactivates the power supply. All the charging unit is under control of an intelligent charging network. The power supply is controlled by CMS and all charging activities are automatically switched. The EVs whose charging service is not accepted by system are parked at non charging area.

[9] described research review of static and dynamic wireless electric vehicle charging system. It describes information regarding wireless charging as it is proposed in high power application, including EVs. Wireless charging has many advantages over plug in charging cause of its simplicity, reliability and user friendliness. The limitation is it can be utilized when vehicle is in stationary mode, like in parking.

[10] provided a snapshot of wireless charging technology. This paper mentioned that electricity is going to be major part of transportation, due to EVs. While wireless charging plays important role in charging facilitate to $\mathrm{EV}$, since it provides an efficient and flexible means of charging. Also, standardization of this technology is underway which will give more 
flexibility and freedom to charge vehicle at any wireless enable parking slot.

[11] With increasing the number of Electrical Vehicles $(\mathrm{EVs})$ there is need to construct new charging infra structures. Compared with plugs and wire, wireless charging is more efficient. This paper studies the basic principle of resonant inductive power transfer which is commonly used in wireless charging. With increasing number of these EVs it is need to solve problem related to it. There are basically three types of charging method are battery swap, conductive charging and wireless charging transfer respectively. Now a days Electrical Vehicles industry is developing world widely with full speed which brings varies charging infrastructure in market. But still wireless power transfer has some difficulties due to lack of complete and exhaustive standards.

[12] presented a review on smart parking system. Proposed system has implemented smart parking system which is onsite deployment of slot model that is used to monitor the free space and book a parking slot. Smart parking can increase the economy by reducing fuel consumption and pollution in cities. Smart parking can be considered as one of the applications of IoT. It also gives facility for booking slots. Once he enters the slot time period will get started later user leave the slot, he needs to pay the amount for the period of time is placed his car in slot.

\section{SYSTEM ARCHITECTURE}

\section{A. Wireless Charging System}

Conductive charging and wireless charging are the different methods to charge an electric vehicle. Some challenges in conductive charging methods are charging time, physical plugging the wire, safety concern. Wireless charging has advantages as it is safe and convenient for charging the vehicle when vehicle is at rest or in motion. Wireless charging can be done by three different modes, 1) static charging, 2) quasi- dynamic charging, and 3) dynamic charging [14]. Compared to conductive power transfer, WPT is more convenient, electric shock protected and effective way to charge. The WPT is a system without any wires and transfers energy through the air gap. WPT is considered as a convenient method for charging EV [6]. This paper is also covering various aspects of wireless charging of electric vehicles, fundamental operation of wireless charging system including inductive wireless charging technique.

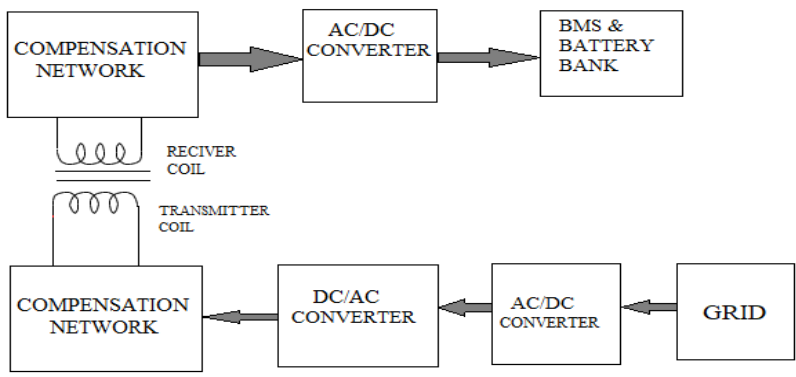

Fig. 1. Basic Digram of Wireless Charging System for EV

\section{B. Fundamental Operating Principle}

The basic block diagram of the static WCS for EVs is shown in above Fig. Firstly, AC mains supply from grid is converted into high frequency $\mathrm{AC}$ using $\mathrm{AC} / \mathrm{DC}$ and DC/AC converters, to enable power transfer from transmission coil to receiving coil. On both transmitting and receiving sides, include series and parallel combination-based compensation networks in order to improve system efficiency. High frequency $\mathrm{AC}$ goes to the transmitting coil which is mounted on ground or concrete through compensation network. The receiving coil, mounted underneath the vehicle, converts oscillating magnetic flux fields into high frequency $\mathrm{AC}$ then high frequency AC is converted to stable DC supply. This DC supply is used by on board batteries. To avoid health and safety issues and ensure stable operation, this system also includes battery management system (BMS), power control and communication.

\section{Inductive Power Transfer}

Inductive power transfer method delivers power wirelessly via magnetic coupling from a static transmitter to secondary receiver. In between primary source and secondary load there is a large air gap [13]. The power transfer efficiency depends on the coil alignment and air gap distance varies between source and receiver [9]. With increase in air gap, the power transfer efficiency decreases. Magnetic coupling coefficient defines the degree of close coupling between the primary and secondary winding [14]. The inductive coupling consists of two coils. The current in the sending coil produces a magnetic field, which passes via the distance and excites the receiving coil due to flux, thus power is transferred. According to [6], inductive coupling is only useful in small distance. If distance is increased between coils, coupling coefficient will drop drastically with air gap. This is not efficient for EV charging. So, another method named as resonant inductive coupling has benefit over the inductive coupling. In this method coil is tuned to its resonance with the help of capacitor.

\begin{tabular}{|c|c|c|c|c|c|}
\hline $\begin{array}{l}\text { TABLE I } \\
\text { Wireless } \\
\text { charging } \\
\text { methods }\end{array}$ & Frequency & Efficiency & $\begin{array}{c}\text { Cost } \\
\& \\
\text { Size }\end{array}$ & $\begin{array}{c}\text { EMI \& } \\
\text { Complexity }\end{array}$ & $\begin{array}{l}\text { Power } \\
\text { Level }\end{array}$ \\
\hline $\begin{array}{l}\text { Inductive } \\
\text { power } \\
\text { transfer } \\
\text { (IPT) }\end{array}$ & $10-50 \mathrm{kHz}$ & Medium & $\begin{array}{c}\text { Medi } \\
\text { um }\end{array}$ & Medium & $\begin{array}{l}\text { Mediu } \\
\text { m/High }\end{array}$ \\
\hline $\begin{array}{l}\text { Capaciti } \\
\text { ve power } \\
\text { transfer } \\
(\mathrm{CPT})\end{array}$ & $\begin{array}{l}100-500 \\
\mathrm{kHz}\end{array}$ & Low & Low & Medium & Low \\
\hline $\begin{array}{l}\text { Permane } \\
\text { nt } \\
\text { magnet } \\
\text { power } \\
\text { transfer } \\
(\text { PMPT) }\end{array}$ & $\begin{array}{l}100- \\
500 \mathrm{kHz}\end{array}$ & Low & High & High & $\begin{array}{l}\text { Mediu } \\
\text { m/Low }\end{array}$ \\
\hline $\begin{array}{l}\text { Resonant } \\
\text { inductive } \\
\text { power } \\
\text { transfer } \\
\text { (RIPT) }\end{array}$ & $1-20 \mathrm{MHz}$ & Medium & $\begin{array}{c}\text { Medi } \\
\text { um }\end{array}$ & $\begin{array}{l}\text { Medium/Lo } \\
\text { W }\end{array}$ & $\begin{array}{l}\text { Mediu } \\
\text { m/Low }\end{array}$ \\
\hline
\end{tabular}

\section{PARKING ARCHITECTURE}

The below-mentioned figure depicts a parking area where system can be implemented along with the way in which communication happens between various actors. The primary actors that constitute the system are:

a) Sensors: This IR sensor can be placed in every parking space for smart parking system. The IR sensors are used to 
detect the object. It uses a voltage up to 0.5 volts- 0.25 volts. These sensors are easily available at the market and less in cost. It determines whether a parking space is vacant or not. If any vehicle is detected, IR sensor shows output as red otherwise it shows output as green. Then, it sends the data to the micro-controller IoT device by using wireless communication.

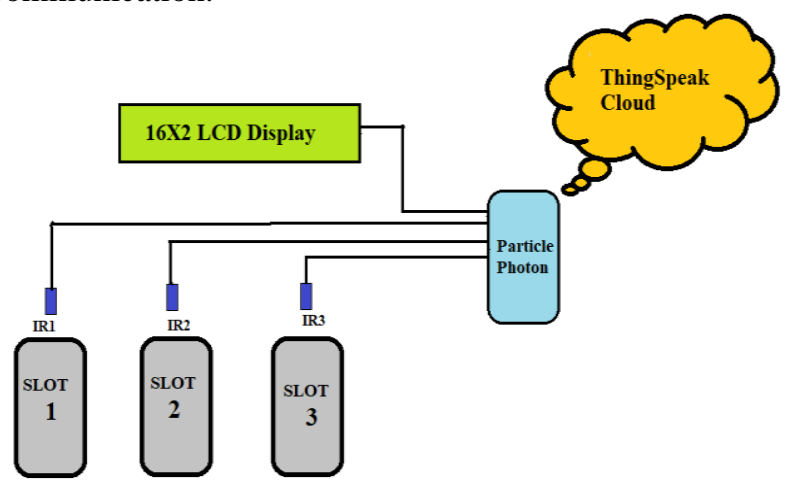

Fig. 2. Block Diagram of IoT Based Car Parking System

b) Processing unit: All the sensors are wirelessly connected to the processing unit. Processing unit is nothing but microcontroller device which is considered as main part of the system. It acts like an intermediate between the sensors and cloud. It collects sensors data using wireless communication and it processes the data. Furthermore, it sends the pro-cessed data which contains the number of free vacant spaces in the parking area to the cloud.

c) The cloud: The cloud will receive the processed data from the processing unit and it done two main tasks. First is to process the received data with help of Google API and store them. Second is to send the information to a user's mobile application. Cloud acts as a data base to store all the records associated with parking areas. It keeps a track of each user connected to the system and maintains information like time at which the car was parked, time duration for parking a car, amount paid by the user and mode of payment. In case of any kind of system failure to quick recovery of data, Continuous backup is made of the data stored on cloud.

\section{OPEN CHALLENGES AND ISSUES}

Now a days, there are various challenges in wireless charging system combined with autonomous parking facility. To improve this combined system following challenges and issue are considered:

- System must stand with all weather conditions like rain, fog etc.

- Internet network range and connectivity in all environmental condition

- Lack of standardization in wireless charging.

- Manage large amount of data.

- Maintenance of all IoT devices is costly.

\section{CURRENT STATE OF ART}

Based on literature survey done the following table gives comparison between various research papers to find out merits and demerits.

\begin{tabular}{|c|c|c|}
\hline $\begin{array}{l}\text { Reference } \\
\text { paper }\end{array}$ & Merits & Demerits \\
\hline $\begin{array}{l}\text { [1] } 2012 \\
\text { Charging } \\
\text { and Parking } \\
\text { System }\end{array}$ & $\begin{array}{l}\text { Use of mobile application } \\
\text { for booking. } \\
\text { Secure }\end{array}$ & $\begin{array}{l}\text { Costly, The difficulty of } \\
\text { understanding }\end{array}$ \\
\hline $\begin{array}{l}{[2] 2013} \\
\text { Parking } \\
\text { System }\end{array}$ & $\begin{array}{l}\text { It provides the slot } \\
\text { information. } \\
\text { It fits in existing parking } \\
\text { system }\end{array}$ & $\begin{array}{l}\text { High cost. } \\
\text { More time required for } \\
\text { implementation. }\end{array}$ \\
\hline $\begin{array}{l}\text { [3] } 2015 \\
\text { Charging } \\
\text { and Parking } \\
\text { System }\end{array}$ & $\begin{array}{l}\text { System deigns its own } \\
\text { schedule of charging for } \\
\text { EVs. }\end{array}$ & $\begin{array}{l}\text { No data generation of } \\
\text { charging. }\end{array}$ \\
\hline $\begin{array}{l}{[4] 2016} \\
\text { Parking } \\
\text { System }\end{array}$ & $\begin{array}{l}\text { Use of mobile appli-cation } \\
\text { for booking. } \\
\text { Use of GPS }\end{array}$ & $\begin{array}{l}\text { Problem in data up- } \\
\text { loading. }\end{array}$ \\
\hline $\begin{array}{l}{[5] 2017} \\
\text { Parking } \\
\text { System }\end{array}$ & $\begin{array}{l}\text { Use of mobile appli-cation, } \\
\text { Automatic data generation }\end{array}$ & $\begin{array}{l}\text { No Protection from } \\
\text { various environmental } \\
\text { conditions }\end{array}$ \\
\hline $\begin{array}{l}{[6] 2017} \\
\text { Charging } \\
\text { System }\end{array}$ & $\begin{array}{l}\text { Save time, Reduce human } \\
\text { error }\end{array}$ & ( \\
\hline $\begin{array}{l}\text { [7] } 2018 \\
\text { Parking }\end{array}$ & $\begin{array}{l}\text { Data can be added or } \\
\text { removed due to flexibility of } \\
\text { cloud }\end{array}$ & $\begin{array}{l}\text { Overload on } \\
\text { microcontroller can crash } \\
\text { the whole system }\end{array}$ \\
\hline $\begin{array}{l}\text { [8] } 2018 \\
\text { Charhing } \\
\text { and Parking } \\
\text { System }\end{array}$ & $\begin{array}{l}\text { Use of charging } \\
\text { management system (CMS) }\end{array}$ & No mobile application \\
\hline $\begin{array}{l}{[9] 2018} \\
\text { Charging } \\
\text { System }\end{array}$ & $\begin{array}{l}\text { Wireless charging is simple } \\
\text { and efficient than pug in } \\
\text { charging. } \\
\text { Used for high power } \\
\text { application }\end{array}$ & $\begin{array}{l}\text { Efficient to use only in } \\
\text { stationary modes. }\end{array}$ \\
\hline $\begin{array}{l}{[10] 2018} \\
\text { Charging } \\
\text { System }\end{array}$ & $\begin{array}{l}\text { It offers an efficient, flexible } \\
\text { means of charging Electric } \\
\text { Vehicles }\end{array}$ & $\begin{array}{l}\text { Lack of Standardization } \\
\text { in wireless charging. }\end{array}$ \\
\hline $\begin{array}{l}{[11] 2019} \\
\text { Charging } \\
\text { System }\end{array}$ & $\begin{array}{l}\text { Wireless charging has more } \\
\text { advantages compare with } \\
\text { plug in charging. }\end{array}$ & - \\
\hline $\begin{array}{l}{[12] 2019} \\
\text { Parking } \\
\text { System }\end{array}$ & $\begin{array}{l}\text { Facility for booking parking } \\
\text { slots }\end{array}$ & $\begin{array}{l}\text { GPS is not used } \\
\text { No data uploading }\end{array}$ \\
\hline
\end{tabular}

\section{CONCLUSION}

Overall, this paper compares various smart parking, charging and combined charging-parking system, which can help to solve various issues related with it. Also, it contains a table of comparison of various research paper. There are various types of methods and techniques used for parking and charging are discussed. There are various sensors, controllers, software and cloud servers are available at market which will help to make system automatic, reliable and user friendly along with development of efficient IoT platform.

\section{REFERENCES}

[1] Julian Timpner, Lars Wolf, "A Back-end System for an Autonomous Parking and Charging System for Electrical Vehicles", Internationa Electrical Vehicle Conference Greenville, SC, USA IEEE 2012

[2] Manjusha Patil, Vasant N. Bhohge, "Wireless Sensor Network and RFID for Smart Parking System", International Journal of Engineering Technology and Advanced Engineering, Volume 3, Issue 4, April 2013, IJETAE

[3] Mehmet Sukru Kuran, Aline Carnerio Viana, Luigi Iannone, Daniel Kofman, Gregory Mermound, Jean P. Vasseur, “A Smart Parking 
Lot Management System for Scheduling the Recharging of Electric Vehicles", IEEE Transaction on Smart Grid November 2015

[4] Abhirup Khanna, Rishi Anand, "IoT based Smart Parking System", International Conference on Internet of Things and Applications (IOTA), Maharashtra Institute of Technology, Pune, India, pp. 266270, 22 Jan-24 Jan, 2016. IEEE

[5] Aniket Gupta, Sujata Kulkarni, et al, "Smart Car Parking Management System Using IoT", American Journal of Science, Engineering and Technology. Vol. 2, pp. 112-119, November 30, 2017.

[6] Adilet Sultanbek, Auyez Khassenov, Yerassyl Kanapyanov, Madina Kenzhegaliyeva, Mehdi Nagheri, "Intelligent Wireless Charging Station for Electrical Vehicles", International Siberian Conference on Control and Communication, 2017, IEEE

[7] Nazish Fatima, Akshaya Natlkar, Pratiksha Jagtap, Sneh Chooudhari, "IoT Based Smart Car Parking System for Smart Cities", International Journal of Advance Research, Ideas and Innovations In Technology, Vol. 4, Issue 1, 2018, ISSN

[8] Zhe Wei, Yue Li, Yongmin Zhang, Lin Cal, "Intelligent Parking Garage EV Charging Scheduling Considering Battery Charging Characteristic", IEEE Transaction on Industrial Electronics, Vol 65, 3 March 2018

[9] Chirag Panchal, et al, "Review of static and dynamic wireless electric vehicle charging system", Engineering Science and Technology, an International Journal, pp.922-937, 21 June 2018.

[10] Morris Kesler, "Wireless Charging of Electrical Vehicles", WiTricity Corporation, Watertown, MA, USA, 2018. IEEE

[11] Songyan Niu, Haiqi Xu, Zhirui Sun, Z. Y. Shao, Linni Jian, "The State of The Arts of Wireless Electrical Vehicle Charging via Magnetic Resonance: Principles, Standards and Core Technologies", Journal of Renewable and Sustainable Energy Reviews, 2019

[12] Anusha, Arshita M S, Anushri, Geetanjali Bishtannavar, Ms. Megha D Hegde, "Review Paper on Smart Parking System", International Journal of Engineering Research and Technology, Vol. 7, 2019 IJERT

[13] Shital khutwad, Shruti Gaur, "Wireless Charging System for Electric Vehicles", International conference on Signal Processing, Communication, Power and Embedded System (SCOPES), 2016.IEEE

[14] Aqueel Ahmad, et al, "A Comprehensive Review of Wireless Charging Technologies for Electric Vehicles", IEEE Transaction on Transportation Electrification Vol.4, pp. 38-63 2017.IEEE

[15] Sahil Rupani, Nishant Doshi, "A review on smart parking using internet on things (IOT)", The 3rd International Workshop on Recent advances on Internet of Things: Technology and Application Approches (IoT-T\&A 2019) Nov 2019, Coimbra, Portugal.
[16] Saeed D. Manshadi, et al, "Wireless Charging of Electric Vehicles in Electricity and Transportation Networks", IEEE Transaction on Smart Grid, Vol 9,pp. 4503-4512,31 Jan 2017,IEEE

[17] Md M. RANA, WEI XIANG, "Internet of Things Infrastructure for Wireless Power Transfer Systems", IEEE Access, volume 6, pp.19295-19303, 24 Jan 2018.IEEE 